\title{
Du rouge au jaune
}

La page de couverture au fil du temps

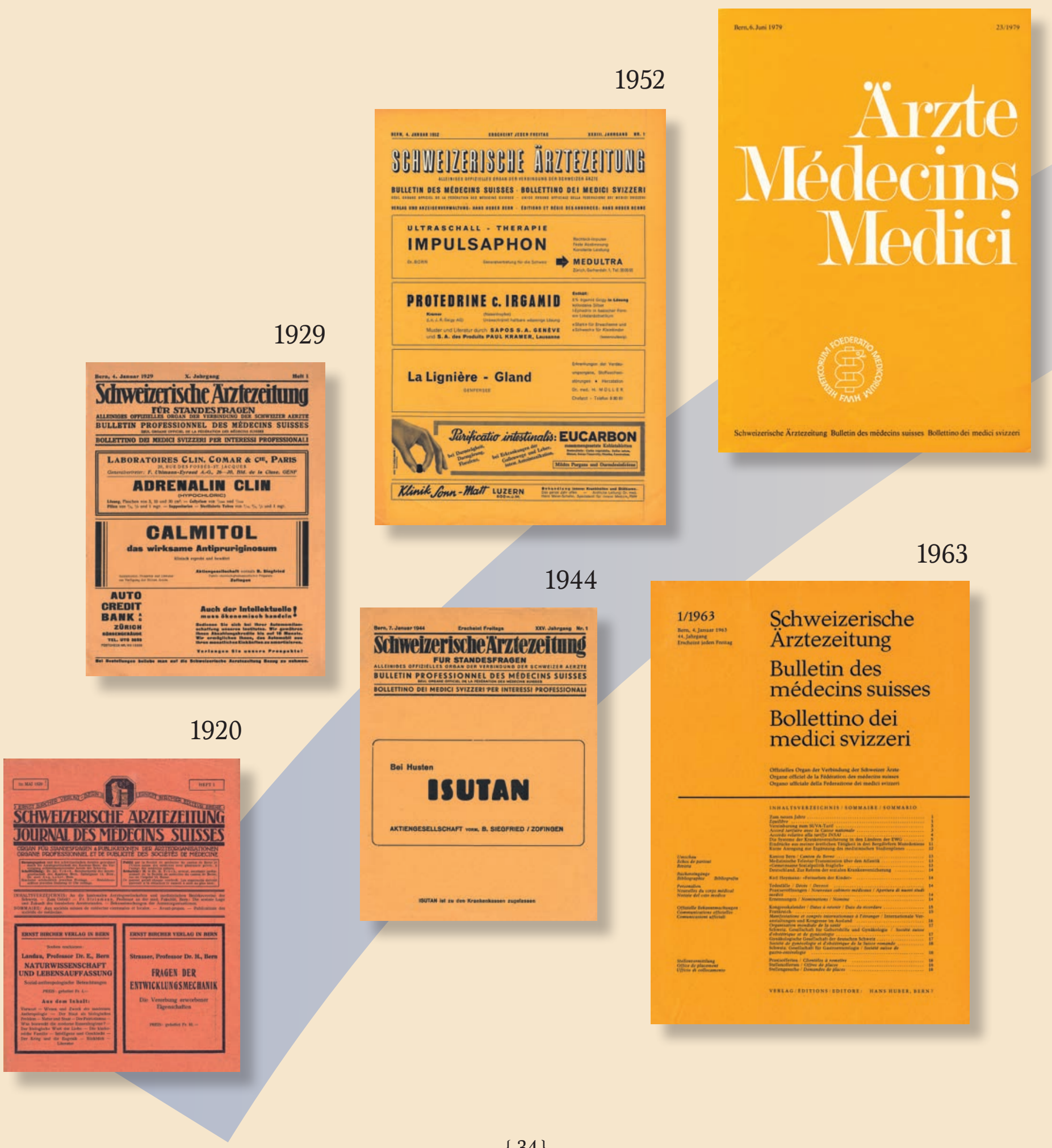


1995

\section{$\$ \mathrm{FMH}=$}

Schweizerische Ärztezeitung

Bulletin des médecins suisses

Bollettino dei medici svizzeri

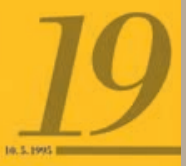

1989

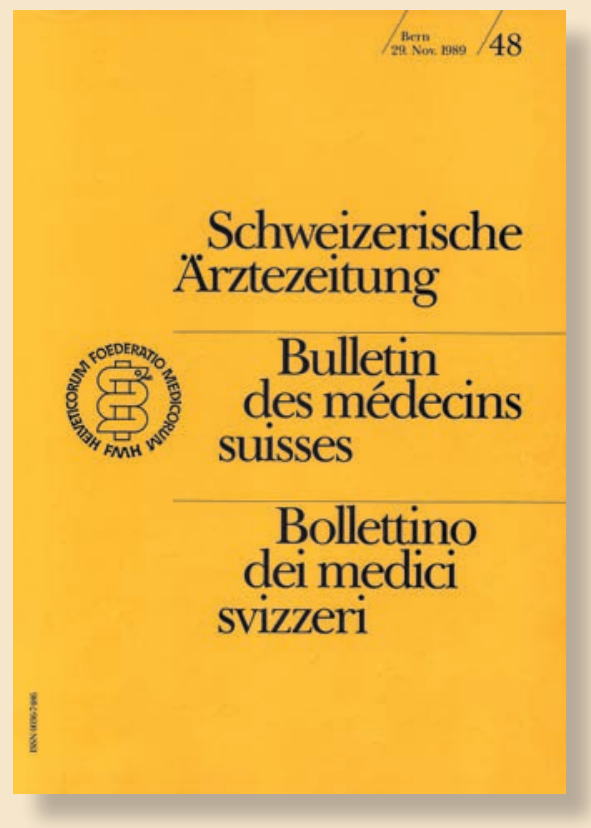

2002

15

Schweizerische Ärztezeitung Bulletin des médecins suisses Bollettino dei medici svizzeri

Jahresbericht 2001 der FMH Guideline: Oberwachung und Management bei Oberschrettun des Geburtstermin

ЕМн 2 пㅜ

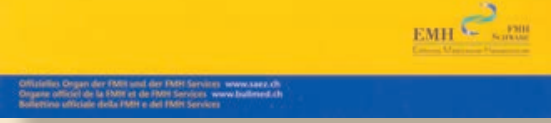

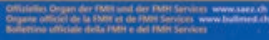

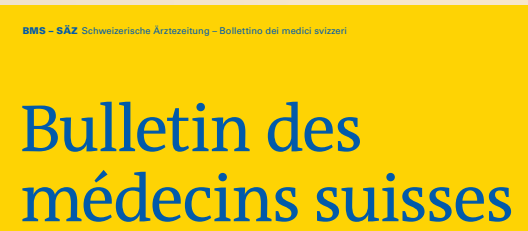

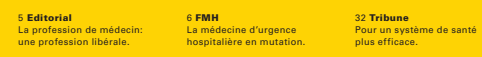

$\stackrel{1}{\underline{1}}$

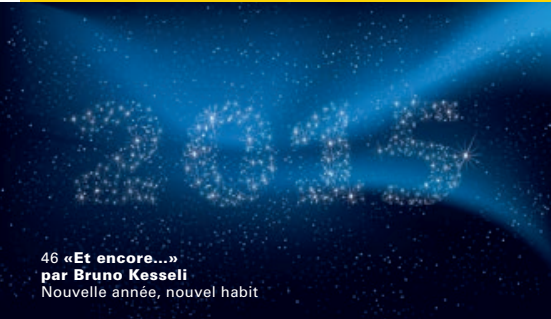

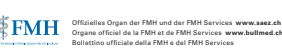

$P_{\text {EMHMedia }}$

1998

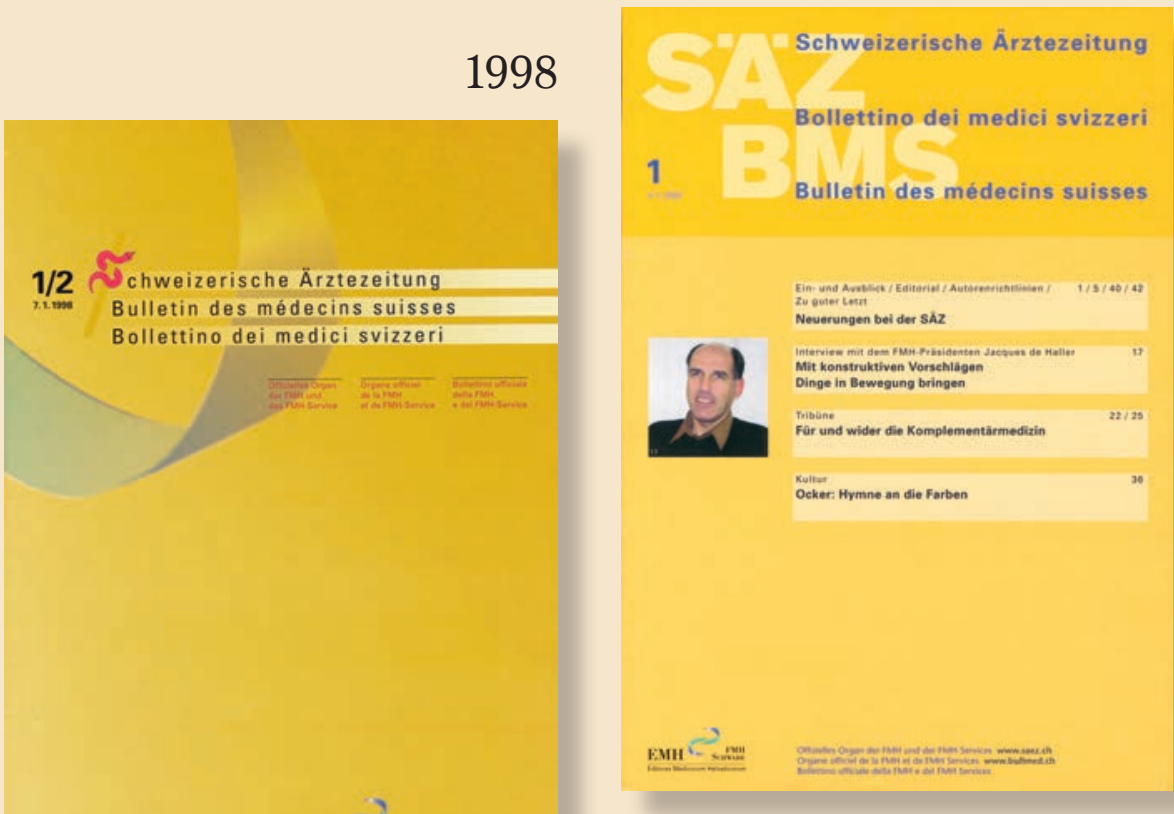

2006

EMH - saikit 